\title{
INVENTORY AND ASSESSMENT OF CORIANDER CROP IN THE STATE OF RAJASTHAN USING MULTITEMPORAL REMOTE SENSING DATA
}

\author{
Shreya Roy*, Niti Singh, P. Kumar, , M.M Kimothi and S. Mamatha \\ Mahalanobis National Crop Forecast Centre, DAC\&FW, New Delhi 110 012, India - (royshreya406, \\ niti.geoinfo,drmmkimothi)@gmail.com,pradeep.kumar82@gov.in,mamatha.ncfc@nic.in
}

\author{
Commission III, WG III/10
}

KEY WORDS: Coriander, Multitemporal, Remote Sensing, Sentinel 2A, Inventory, Classification, Accuracy

\begin{abstract}
:
The present study aims to develop the methodology for inventory and assessment of coriander crop in Rajasthan using remote sensing technique. Sentinel-2A optical data having a spatial resolution of $10 \mathrm{~m}$, from January-March, 2017 were considered for this study keeping in mind the crop calendar. It was found that coriander at its flowering stage gives a distinct light pink colour which helps it to differentiate from other crops. However it is difficult to separate other stages of coriander (early vegetative, mature stage) owing to its similarity in tonal pattern with mustard. The overall accuracy of single date image was found to be $63.29 \%$ and Kappa $\left(\mathrm{K}^{\wedge}\right)$ Coefficient as 0.5532 . With the inclusion of multiple dates accuracy increased to $91.14 \%$ and Kappa $\left(\mathrm{K}^{\wedge}\right)$ Coefficient to 0.7436 . This was because increase in information increases the possibility to separate crops from each other. This study demonstrates the feasibility of multi-temporal satellite data for accurate coriander crop mapping area estimation in multi-crop scenario with reasonable accuracy at the Block/district level and State level.
\end{abstract}

\section{INTRODUCTION}

Coriander (Coriandrum sativum L.) is an annual seed spice crop, which belongs to family Apiaceae. It is native of Mediterranean region (Bairwa et al., 2017). India is the largest producer, consumer and exporter of coriander seed. It is mainly cultivated in Rajasthan, Madhya Pradesh, Uttar Pradesh and Southern States like Andhra Pradesh, Karnataka and Tamil Nadu. It is mostly grown as a Rabi season crop and sowing is done between middle of October to middle of November (Coriander Crop Cultivation Guide, India AgroNet). The spice is an important item of international trade (Sharma et al., 2014). Thus accurate assessment of its area, condition and production is essential for advance planning.

Satellite remote sensing plays a valuable role in crop inventory, yield estimation and crop condition monitoring (Dhumal et al., 2013 ; Singh et al., 2017). However, proper crop identification is one of the prerequisite for crop acreage and production estimation (Kalpana et al., 2003). Depending on geographic area, crop diversity, field size,crop phenology and soil condition different band ratios of multispectral data and classifications schemes can be used (Nellis et al., 2009).

Multi-temporal datasets have been proven to be superior to single date datasets when it comes to crop distinguishability (Conrad et al., 2010). During different growth stages plant structure, pigment and plant assemblages vary, which means that the spectral profile changes over time. Crops which are spectrally similar at some moment in time, can thus differ at other moments, which can make the discrimination between these crops easier (Murthy et al., 2003; Simonneaux et al., 2008).

Studies have shown (Dutta et al., 1998; Manjunath et al., 1998) that incorporation of multi temporal satellite data helps in improving the classification accuracy. In a study multi date IRS LISS III data was used for identification of mustard, potato \& wheat crops in Uttar Pradesh. It was possible to discriminate and map them with high accuracy in multidate whereas single date is only good for homogeneous area and reduce data volume (Vyas et al., 2005).

Vegetation indices also prove useful in crop type classification (Carlson et al., 1997). The main goal is to enhance the vegetation signal (Chuvieco et al., 2009). An advantage of these indices is that they combine multiple bands to calculate a single index image which contains the most relevant information. In a multi-temporal dataset each band represents a date instead of measured reflectances at a certain bandwidth (Ommeren, 2016).

This study is a part of pilot study in a National level project CHAMAN (Coordinated Horticulture Assessment and Management using Geo-informatics) under the MIDH (Mission for Integrated Development of Horticulture) of Ministry of Agriculture \& Farmers' Welfare. CHAMAN is formulated for better horticulture inventory \& management in selected districts of major states (Ray et al., 2016).

In this study, Major coriander growing districts of Rajasthan namely, Jhalwar, Baran and Kota were chosen. Coriander acreage estimation was carried out using multitemporal satellite data and GPS field data collected using the smartphone.

\section{MATERIALS AND METHODS}

\subsection{Study Area}

Rajasthan is the second largest coriander producing state in India and contributes $25 \%$ of India's total production (Figure 1). It is mainly grown in Hadoti region of Rajasthan comprising of Kota, Baran and Jhalawar districts and which, holds the entire production of the state (Bairwa et al., 2017) (Figure 2). Geographically this region lies between Malwa Plateau in the east, Aravali range in the west and Marwar plateau in the west south side, on the border with Madhya Pradesh. The major river

\footnotetext{
* Corresponding author
} 
is the Chambal River, with its tributaries Kalisindh, Parvati and Chakan. The soil is alluvial in nature. Major agriculture crops of this region are soybean, maize, paddy, rapeseed \& mustard, wheat and coriander. In horticulture, fruits like citrus, mango and guava are cultivated. Vegetable crops include tomato, brinjal, potato, onion and garlic (Comprehensive -District Agriculture Plan (CDAP), Kota, Jhalawar, Baran).

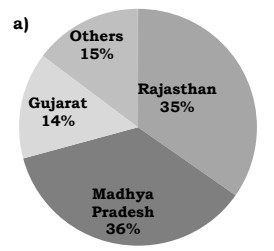

b)
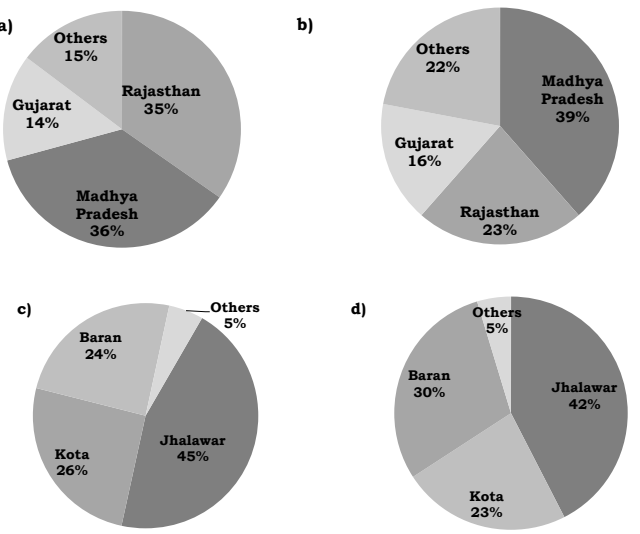

Figure 1. State wise a) area; b) production of coriander in the country, and district wise c) area; d) production in Rajasthan

(Source: www.aps.dac.gov.in/public/report.aspx)

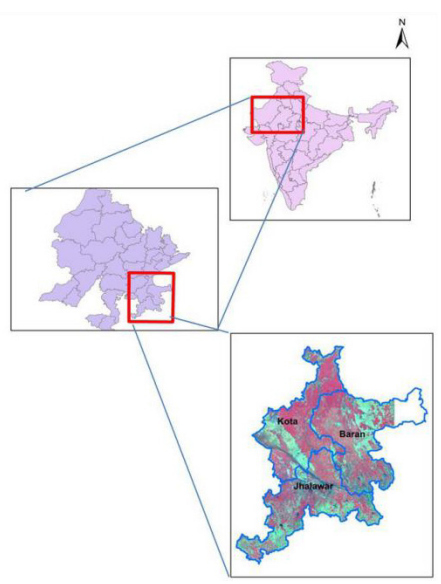

Figure 2. Study Area

\subsection{Data Used}

2.2.1 Remote Sensing Data Used: High resolution temporal satellite data of Sentinel 2a have been used for this study. The details of satellite datasets are given in (Table 1)

\begin{tabular}{lllll}
\hline $\begin{array}{c}\text { Satellite/ } \\
\text { Sensor }\end{array}$ & $\begin{array}{c}\text { Spatial } \\
\text { Resolution }\end{array}$ & $\begin{array}{c}\text { Temporal } \\
\text { Resolution }\end{array}$ & $\begin{array}{c}\text { Spectral } \\
\text { Bands } \\
\text { used }\end{array}$ & Date \\
\hline Sentinel & $10 \mathrm{~m}$ & 10 days & $\begin{array}{l}\text { NIR, } \\
\text { Red, }\end{array}$ & 30 Jan, 09 \\
2a MSI & & & Green 01 & Mar, 2017 \\
\hline
\end{tabular}

Table 1. Satellite Data Used
2.2.2 Ground Truth: Ground truth (GT) survey was carried out in the month of February and March by Rajasthan State Agriculture Department and Regional Remote Sensing Centre, Jodhpur in collaboration with MNCFC. Total 79 GT points were collected using FASAL FDC Android App, on smartphone. The App collects geographic coordinates, photographs and crop information and sends, in real-time to Bhuvan server. The number of GT sties collected for different crops is given in Table, while the GT locations are presented in Figure 3.

\begin{tabular}{|l|c|}
\hline Crop Type & Number \\
\hline Coriander & 19 \\
\hline Garlic & 3 \\
\hline Mustard & 26 \\
\hline Opium & 1 \\
\hline Wheat & 27 \\
\hline Citrus Orchard & 1 \\
\hline Others & 2 \\
\hline
\end{tabular}

Table 2. Ground Truth Details

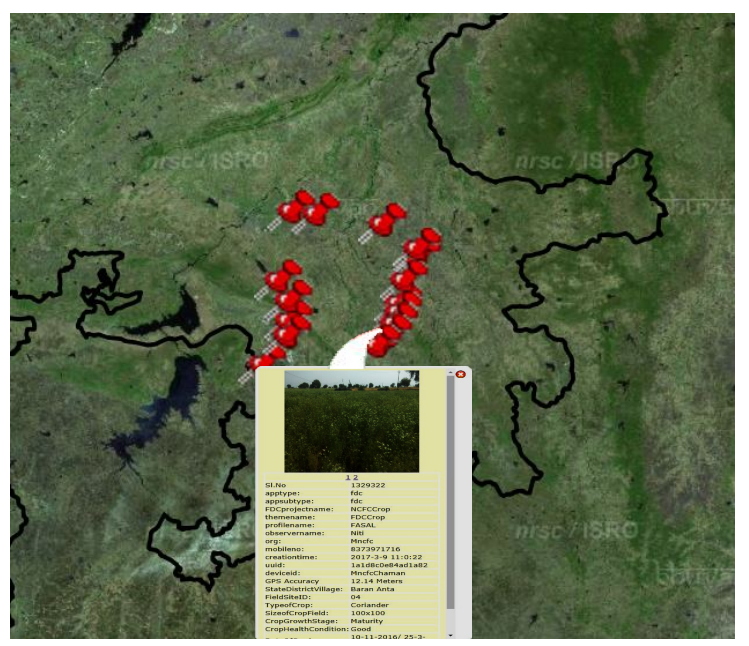

Figure 3. Ground Truth on Bhuvan Portal

2.2.3 Collateral and Statistical data: Four years (2013-14, 2014-15, 2015-16 and 2016-17) statistical data of district level coriander area has been collected from online HAPIS (Horticulture Area Production Information System) portal.

2.2.4 Software Used: i) Erdas Imagine 2015 for satellite image analysis and ii) ArcGIS 10.3 for Mapping

\subsection{Methodology}

2.3.1 Data Preprocessing: Three seasons (January, February and March) Sentinel 2A Data were downloaded from USGS Earth explorer in JPEG 2000 format. It has 12 bands, out of which three bands 3(Green), 4(Red) and band 8(NIR) were layer stacked to form a standard false color composite (FCC). Each season data comes in many tiles which were then mosaicked and subset according to the spatial extent of the study area. Since Sentinel data obtained were already TOA (Top of Atmospheric) corrected there is no need for any radiometric correction. However individual scenes were checked for any shift. 
2.3.2 Spectral Separability Analysis: To check the seperability between training signatures, feature space plots and spectral signatures were created for coriander and other competing crops namely mustard, wheat on Sentinel 2A image dated 9.2.2017. Feature space images generate two dimensional plots of pixel values in two image bands with 8 bit data in a 255 by 255 feature space. These images also show the degree of correlation among two bands. The February image was chosen as all the stages of coriander was present at that time. In addition to the crop class separability at a single date, the multitemporal distinguishability was also checked. To create temporal profiles, NDVI was calculated for each of the images.

2.3.3 Transformed Divergent Analysis: A statistical measure of seperability by Transformed Divergence Analysis was used to determine the interclass separability between competing crops present at different phenelogical stages (Hallada et al., 1982).

Divergence between class pairs $\mathrm{i}$ and $\mathrm{j}$ has been defined as:

$$
\begin{gathered}
D_{i j}=1 / 2 \operatorname{tr}\left[\left(\sum i-\sum j\right)\left(\sum j^{-1}-\sum i^{-1}\right)\right\rfloor+1 / 2 \operatorname{tr}\left[\left(\sum i^{-1}-\right.\right. \\
\left.\left.\sum j^{-1}\right)\left(M_{i}-M_{j}\right)\left(M_{i}-M_{j}\right)\right]^{T}
\end{gathered}
$$

where $\Sigma=$ Class covariance matrix

$\mathrm{M}=$ Vector of class means

$\operatorname{tr}=$ trace (sum of the diagonal elements)

Because divergence increases without bound as statistical separability between classes increases, Swain et al., 1979 defined a saturation transform which provides a measure more closely corresponding to percent correct classification.

The transformed divergence expression is:

$$
\mathrm{TD}_{\mathrm{ij}}=2000\left\lfloor 1-\exp \frac{-\mathrm{D}_{\mathrm{ij}}}{8}\right\rfloor
$$

This measure has a saturating behavior, that is, percent correct classification saturates at 100 percent when a certain level at statistical seperability is reached $(\mathrm{TD}=2,000)$.

2.3.4 Single Date Image Classification: Two step classification approach was followed in the February image (9.2.2017) based solely on the spectral information. In the first step, unsupervised classification using ISODATA (Tou et al., 1974) was performed to remove all the non-vegetation classes and vegetation mask was generated. In the second step supervised classification was performed on the masked image using Maximum Likelihood Classifier (MXL) as it is considered superior to other classifiers (Richards et al., 2005). It assumes that the population from which training samples are drawn are multivariate normal in their distribution. The training signatures of various crops (wheat, mustard, coriander, garlic, opium) orchard, and other vegetation classes were generated with reference to the Ground Truth (GT) sites.

2.3.5 Multitemporal Image Classification: In addition, a classification based on temporal information was also carried out. Since it takes into account differences in phenological development it is easier to separate spectrally similar crops.
2.3.6 Accuracy Assessment: Accuracy assessment is an important step in the classification process. It helps to determine quantitatively how effectively pixels were grouped into the correct feature classes in the area under investigation (Ismail et al., 2008). Confusion matrix (Stehman, 1997) was generated using ground truth for the single date (9.2.2017) as well as in the multitemporal dataset for the accuracy assessment. Additionally, a coefficient of agreement between classified image data and ground reference data were calculated using Kappa $\left(\mathrm{K}^{\wedge}\right)$ coefficient (Cohen, 1960), which takes the random chance of a correct classification into account (Chuvieco et al., 2009; Congalton, 1991 ; Mather et al., 2009). Kappa statistic has been shown to be a statistically more sophisticated measure of classifier agreement and thus gives better interclass discrimination than overall accuracy (Fitzgerald et al., 1994).

2.3.7 Quality Check and Refinement: District wise internal quality check was performed and necessary refinement was applied to image.

2.3.8 Area Estimation: Coriander area for the districts of Baran, Kota and Jhalwar was computed in ERDAS Imagine using zonal attribute. The district wise areas were then added and multiplied with a extrapolation factor (calculated from last 4 years' HAPIS/state horticulture data) to get the state level area. It was then was validated with statistics obtained from online HAPIS (Horticulture Area Production Information System) portal for the state of Rajasthan as well as reported statistics of the year 2016-17 collected from the state horticulture department during ground truth The percent relative deviation was computed.

Overall Methodology is given in Figure 4.

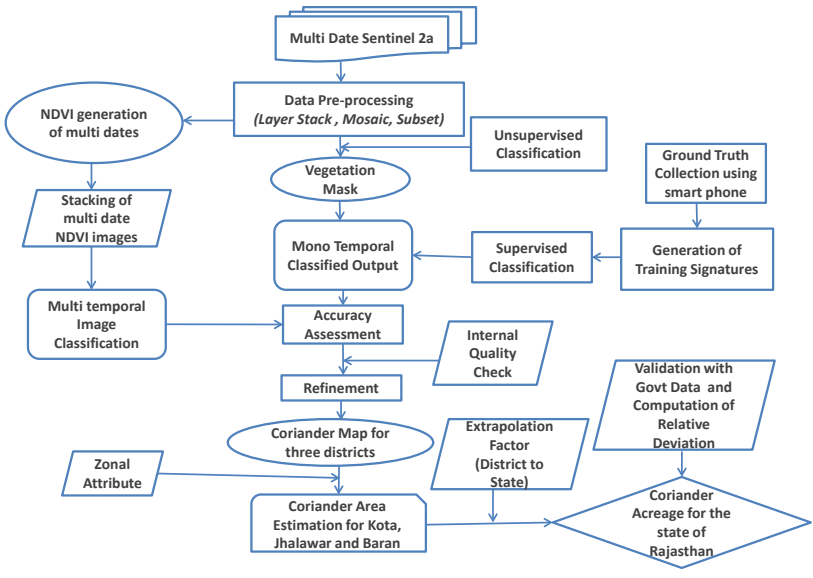

Figure 4. Methodology Flowchart

\section{RESULTS AND DISCUSSION}

Tonal variations of different competing crops have been shown in Figure 5. The date of image acquisition was in the month of February. In visual comparison with competing crops it has been observed that, in this period wheat is at its vegetative stage giving a characteristic bright red tone due to a higher reflectance in the NIR region; Mustard is at its mature stage giving a light magenta tone. Garlic and Orchard areas have similar tonal characteristic of dull red to maroon. Only difference is that 
garlic is a short duration crop and orchards are perennial crops. Coriander at its flowering stage gives a characteristic light pink tone which is entirely different from other surrounding crops. However it is difficult to separate other stages of coriander (early vegetative, mature stage) owing to its similarity in tonal pattern.
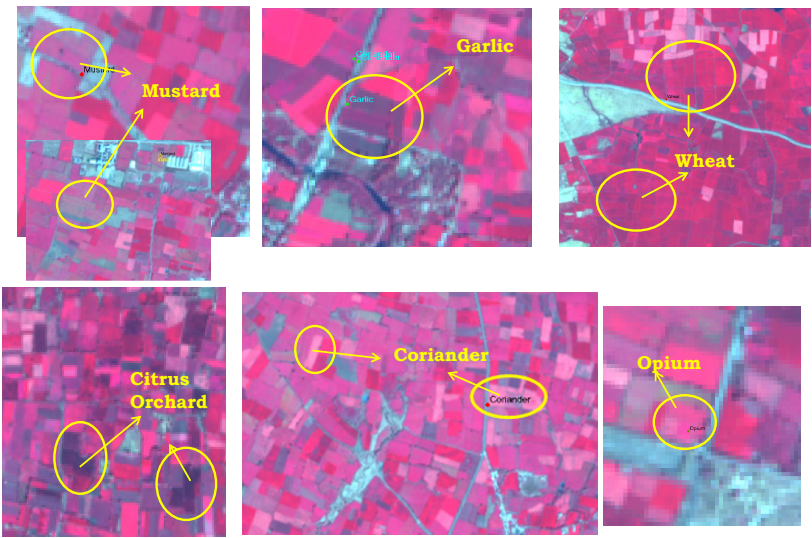

Figure 5. Tonal Variations of Different Competing Crops.

Data: Sentinel 2a MSI, 9-Feb 2017

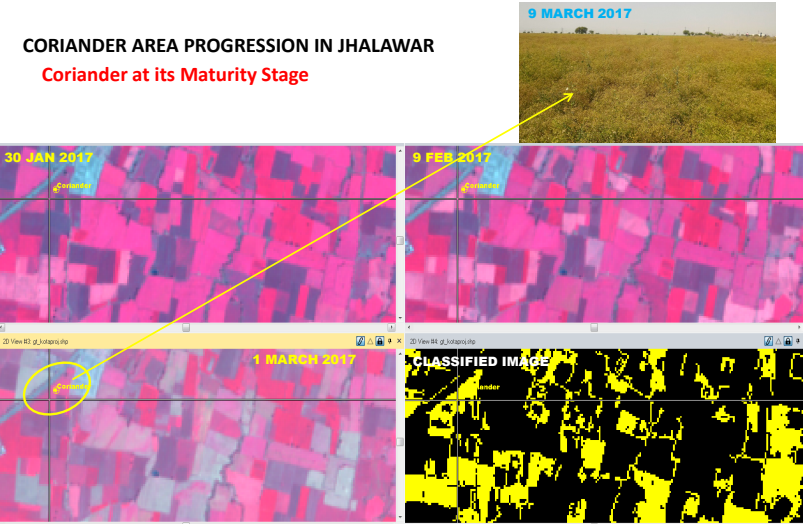

Figure 6. The Field Photograph was collected on $9^{\text {th }}$ March 2017 when most of the fields were in mature stage. In some patches however coriander was still at its flowering stage

To evaluate separability of different competing crops on monotemporal image of 9th February 2017, feature space plot (Figure 7) of different training signatures was generated with 95 percent confidence ellipse. Reflectance from Red band was plotted on $\mathrm{X}$ axis and NIR band on $\mathrm{Y}$ axis. 95 percent confidence ellipses represent the pixels assigned to each object area using a maximum likelihood classifier with 2 standard deviation from the mean (Ommeren, 2016). Dasgupta et.al., (2013) showed a single class of a single parameter with mean $\mu$ and standard deviation $\sigma$, the values falling beyond $\mu+2 \sigma$ and $\mu$ $-2 \sigma$ are not representing that class, but a transitional zone between two subsequent classes. Hence this threshold was chosen as a decision boundary to separate two class.

Looking at the feature space plot, it becomes clear that wheat and coriander at flowering stage was easier to separate on the February image. However there was considerable spectral overlap with mustard and coriander at mature and vegetative stage owing to similar reflectance pattern. Mean spectral profile of different crops (Figure 8) also conforms the same.

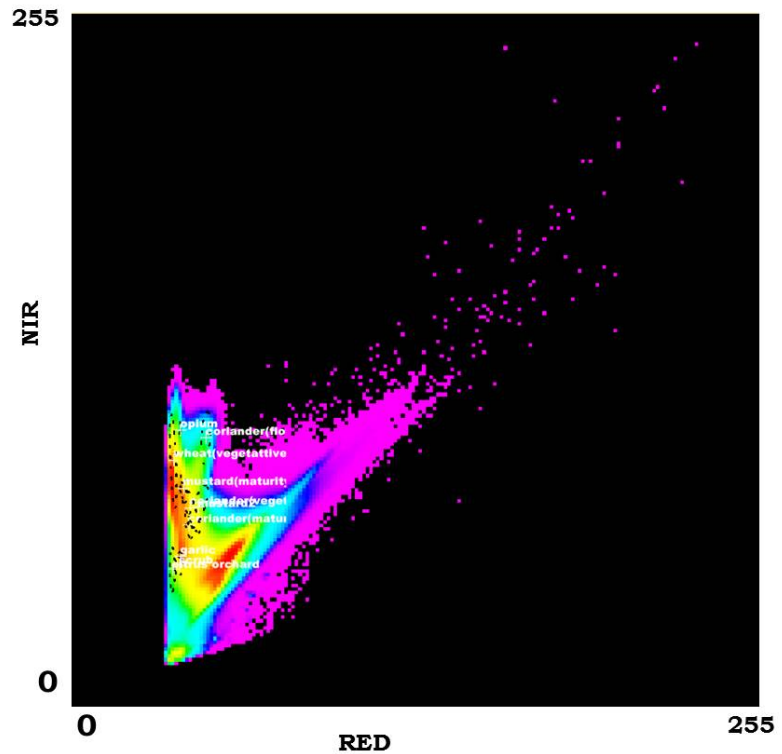

Figure 7. Feature Space plot of Red and NIR with 95 percent confidence ellipse.

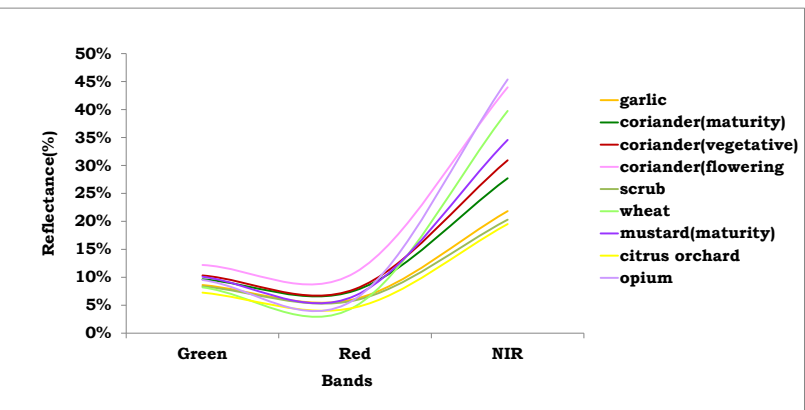

Figure 8. Mean spectral profile of different crops on Sentinel 2A MSI data of $9^{\text {th }}$ February

The temporal profiles of the crop classes as shown in Figure 9 on the other hand showed an increase in distinguishability compared to the spectral profiles based on a single image. Three classes of coriander was identified which represents three stages (vegetative, flowering and maturity) present at a time. It was clearly seen that there was a mixing with one stage of coriander with the mustard in the month of February but in the month of March both gets separated.

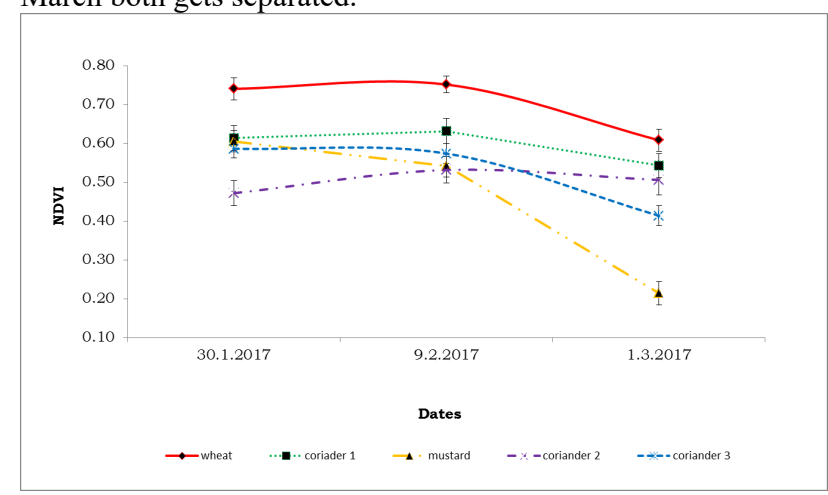

Figure 9. Temporal spectral profiles of different crops showing mean and standard deviation 
Statistical separability was also analysed between the signatures by computing Transformed Divergence Analysis as shown in Figure 10. According to Jensen, 1996 the transformed divergence "gives an exponentially decreasing weight to increasing distances between the classes." The scale of the divergence values can range from 0 to 2,000 . As a general rule, if the result is greater than 1,900, then the classes can be separated. Between 1,700 and 1,900, the separation is fairly good. Below 1,700, the separation is poor.

The graph below shows wheat, mustard and coriander flowering stage are easily separable from each other. However there is some mixing between other stages of coriander with that of mustard in a mono temporal image.

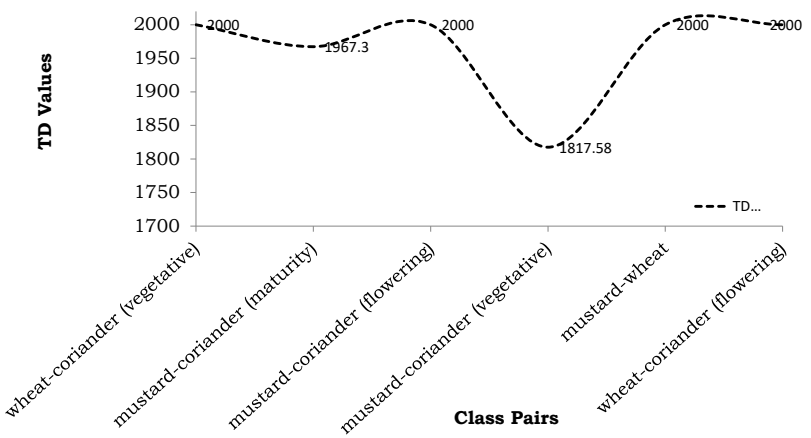

Figure 10. Transformed Divergence Analysis between different class pairs as shown in image 9.2.2017

Thus it can be concluded single date imagery is not optimum for accurate crop discrimination for this type of multi crop scenarios. January and March data have to be considered for coriander mapping in order to capture early and late coriander classes.

Accuracy assessment was carried out for both in mono temporal and multi temporal image classification. Paul, 1991 recommended that a standard of $85 \%$ accuracy is acceptable level of digital image classification. Also the agreement criteria for Kappa $\left(\mathrm{K}^{\wedge}\right)$ statistic was defined by Landis et al., 1977. The agreement is poor when $\mathrm{K}<0.4$, good when $0.4<\mathrm{K}<0.7$ and excellent when $\mathrm{K}>0.75$.

Table 3 below shows an overall accuracy of $63.29 \%$ with 79 ground control points for mono temporal image classification. Wheat shows User's accuracy of $100 \%$ and Producer's accuracy of $96.3 \%$; Coriander at its flowering stage shows User's accuracy of $100 \%$ and Producer's accuracy of $72.7 \%$; On the other hand mustard shows very poor User's and Producer's Accuracy along with other stages of coriander. This was due to mixing between the crops in a single date. Kappa $\left(\mathrm{K}^{\wedge}\right)$ Coefficient was obtained as 0.5532 .

\begin{tabular}{lll}
\hline Class & $\begin{array}{l}\text { User's } \\
\text { Accuracy }\end{array}$ & $\begin{array}{l}\text { Producer's } \\
\text { Accuracy }\end{array}$ \\
\hline Garlic & $100 \%$ & $100 \%$ \\
Mustard (Vegetative) & $44.4 \%$ & $80 \%$ \\
Coriander(Maturity) & $20 \%$ & $33.3 \%$ \\
Coriander(Vegetative) & $25 \%$ & $80 \%$ \\
Mustard(Maturity) & $75 \%$ & $30 \%$ \\
Coriander(Flowering) & $100 \%$ & $72.7 \%$ \\
Wheat(Vegetative) & $100 \%$ & $80 . \%$ \\
\hline
\end{tabular}

Table 3. Accuracy Assessment
In Multitemporal image classification, the overall accuracy was 91.14\% and Kappa $\left(\mathrm{K}^{\wedge}\right)$ Coefficient as 0.7436 . According to the agreement scale mentioned above, multitemporal classification denotes very good to excellent agreement than mono temporal one.

The total coriander area of three districts was estimated as 199.2 thousand hectares, which was then extrapolated to state level using a factor of 1.1. The total area under coriander for the state of Rajasthan was estimated to be 219.1 thousand, which showed a relative deviation of $-0.06 \%$ from the official figures.

\begin{tabular}{|c|c|c|c|c|c|}
\hline \multirow[b]{3}{*}{ District } & \multicolumn{3}{|c|}{ Area in ' $000 \mathrm{Ha}$} & \multicolumn{2}{|c|}{ Percentage } \\
\hline & RS Estimate & $\begin{array}{c}4 \text { years } \\
\text { average } \\
\text { area } \\
(2013-14 \\
\text { to } 2016- \\
17)\end{array}$ & $\begin{array}{c}\text { Rajasthan } \\
\text { State Govt } \\
\text { Data }\end{array}$ & Relative D & Peviation \\
\hline & \begin{tabular}{|l|} 
(a) \\
\end{tabular} & \begin{tabular}{|l|} 
(b) \\
\end{tabular} & (c) & $\{(b-a) / b\} * 100$ & $\{(c-a) / c\} * 100$ \\
\hline BARAN & 53.8 & 50.5 & 45 & -6.61 & -19.56 \\
\hline JHALAWAR & 91.3 & 93.2 & 98 & 2.07 & 6.86 \\
\hline KOTA & 54.1 & 52.8 & 55 & -2.53 & 1.64 \\
\hline 3 District Total & 199.2 & 196.4 & 198 & -0.01 & -0.60 \\
\hline State Total & 219.1 & 206.7 & & -0.06 & \\
\hline Factor & & 1.1 & & & \\
\hline
\end{tabular}

Table 4. Area Comparison between Remote Sensing Estimate and Government Data ( Source: www.aps.dac.gov.in/ public/report.aspx): Reported statistics from state horticulure department of Rajasthan for the year 2016- 17

\section{CONCLUSION}

The following study shows the role of remote sensing data in estimating area of coriander in Rajasthan. Three seasons Sentinel data (30-1-2017, 9-2-2017 and 1-3-2017) having temporal resolution of 10 days, was used for coriander mapping as single date data in the month of February was not suitable in multicrop scenarios like this. Overall Classification Accuracy was also increased by the inclusion of multiple dates as different phenological stages helped in crop discrimination.

\section{ACKNOWLEDGEMENT}

The study was conducted under the CHAMAN (Coordinated Horticulture Assessment and Management using geoiNformatics) project under the Mission for Integrated Development of Horticulture (MIDH) of Department of Agriculture, Cooperation and Farmer's Welfare. Authors are grateful to Dr. S. S. Ray, Director, MNCFC for his constant encourage, technical guidance for the work and review of the paper. Authors are thankful to Regional Remote Sensing Centre, Jodhpur for their cooperation and logistic support for carrying out ground truth.

\section{REFERENCES}

Bairwa, R.K., Dhaka, B.L., Poonia, M.K., Nagar, B.L., Balai, C.M. (2017). Coriander a Potential Seed Spice Crop of Humid South Eastern Plains-Zone of Rajasthan, India. International 
Journal of Current Microbiology and Applied Sciences, 6(4), pp. 2385-2391.

Carlson, T.N., Ripley, D.A. (1997).On the relation between NDVI, Fractional Vegetation Cover and Leaf Area Index. Remote Sensing of Environment, 62(3), pp. 241-252.

Chuvieco, E., \& Huete, A. (2009). Fundamentals of satellite remote sensing. Boca Raton: CRC Press Inc.

Cohen, J. (1960). A coefficient of agreement for nominal scales. Educational and Psychological Measurement. 20 (1), pp. 3746.

Comprehensive -District Agriculture Plan (CDAP), Kota, Jhalawar, Baran.

Congalton, R. G. (1991). A review of assessing the accuracy of classifications of remotely sensed data. Remote Sensing of Environment, 37(1), pp. 35-46.

Conrad, C., Fritsch, S., Zeidler, J., Rücker, G., \& Dech, S. (2010). Per-field irrigated crop classification in arid Central Asia using SPOT and ASTER data. Remote Sensing, 2(4), pp. 1035-1056.

Coriander Crop Cultivation Guide, India Agro Net.

Dasgupta, A., Sastry, K.L.N., Dhinwa, P.S., Rathore, V.S., Nathawat, M.S.(2013). Identifying desertification risk areas using fuzzy membership and geospatial technique - A case study, Kota District, Rajasthan Journal of Earth System. Science, 122 (4), pp. 1107-1124.

Dhumal, R.K., Rajendra, Y., Kale, K.V., Mehrotra, S.C.(2013). Classification of Crops from remotely sensed Images: An Overview. International Journal of Engineering Research and Applications, pp. 3(3), 758-761.

Dutta, S., Patel, N.K., Medhavy, T.T., Srivastava, S.K., Mishra, N., Singh, K.R.P. (1998). Wheat crop classification using multidate IRS LISS-I data. Journal of the Indian Society of Remote Sensing. 26(1), pp. 7-14.

Fitzgerald, R.W., Lees, B.G. (1994). Assessing the classification accuracy of multi-sources remote sensing data. Remote Sensing of Environment, 47, pp. 362-368.

Hallada, W., Bly, B.G., Boyd, R.K., Cox, S.(1982). A study of feature extraction using divergence analysis of texture features. Proceedings of the National Conference on Energy Resource Management. Volume 1, NASA Goddard Flight Centre, Maryland, U.S.A.

Ismail, M.H., Jusoff, K. (2008). Satellite Data Classification Accuracy Assessment Based from Reference Dataset. International Journal of Geological and Environmental Engineering Volume 2(3), pp. 23-29.

Jensen, J.R. (1996). Introductory digital image processing. A remote sensing perspective. 2nd Edition, Prentice Hall, Englewood, NJ.

Kalpana, R., Natarajan, S., Mythili, S., Shekinath, D.E., Krishnarajan, J.(2003). Remote Sensing for Crop Monitoring-A review. Agricultural Reviews, 24(1), pp. 31-39.

Landis, J. R.., \& Koch G, G., (1977). The measurement of observer agreement for categorical data. Biometrics 33 (1), pp. 159-174.

Manjunath, K., R., Kundu, N., Panigrahy, S. (1998). Evaluation of spectral bands and spatial resolution of LISS II and LISS III sensors on-board IRS satellites for crop identification. Journal of the Indian Society of Remote Sensing, 26(4), pp. 197-208.

Mather, P., \& Tso, B. (2009). Classification methods for remotely sensed data. Boca Raton: CRC press.

Murthy, C.S., Raju, P.V., Badrinath, K.V.S.(2003). Classification of wheat crop with multi-temporal images: performance of maximum likelihood and artificial neural networks. International Journal of Remote Sensing, 24(23), pp. 4871-4890.

Nellis, M., Duane, Kevin P., Price, Donald, R. (2009). Remote sensing of cropland agriculture. The SAGE Handbook of Remote Sensing, 1, pp. 368-380.

Ommeren, van W. L. (2016). Remote Sensing and Crop Recognition Improving the information system supporting small holders in Mali. A thesis submitted in partial fulfilment of the degree of Master of Science at Wageningen University and Research Centre, The Netherlands.

Paul, M. (1991). Computer processing of remotely sensed images: An introduction, Biddley Limited Publication.352p

Ray, S.S., Mamatha, S, Manjunath, K.R., Uday, R., Seshasai, M.V.R., Singh, K.K., Kimothi, M.M., Parihar, J.S. \& Saxena, M.(2016). CHAMAN: A National Level Programme for Horticultural Assessment \& Development. Bulletin of the National Natural Resources Management System, NNRMS (B), pp. 1-6.

Richards, A.J., Jia, Xiuping. (2005). Remote Sensing Digital Image Analysis, 4rth Edition, 203.

Sharma, R.P., Singh, R.S., Verma, T.P., Tailor, B.L., Sharma, S.S., Singh, S.K.(2014). Coriander the taste of Vegetables: Present and Future Prospectus for Coriander Seed Production in Southeast Rajasthan. Economic Affairs, 59(3), pp. 345-354.

Simonneaux, V., Duchemin, B., Helson, D., Er-raki, S., Olioso, A., Chehboun, A.,G.(2008).The use of high resolution image time series of crop classification and evapotranspiration estimate over an irrigated area in central Morocco. International Journal of Remote Sensing, Taylor and Francis, 29(1), pp. 95116.

Singh, V., Patel, A.N., Dalwadi, A., Kathota, J., Suthar, J., Kalubarne, M.H. (2017). Horticulture Fruit Crop Plantations Mapping using Geoinformatics Technology in Gujarat State, India. International Journal of Advanced Remote Sensing and GIS, 6(2), pp. 2033-2049.

Stehman, S. (1997). Estimating standard errors of accuracy assessment statistic under cluster. Remote Sensing of Environment, 62 (1), pp. 77-89.

Swain, P.H., Davis, S.M.(1978). Remote Sensing; The Quantitative Approach, New York: McGraw-Hill.

Tou, J. T., Gonzalez, R.C. (1974). Pattern Recognition Principles, Addison-Wesley Publishing Company, Reading, Massachusetts.

Vyas, S. P., M. P. Oza, V. K. Dadhwal.(2005). Multi-crop separability study of Rabi crops using multi-temporal satellite data. Journal of the Indian Society of Remote Sensing, 33. (1), pp. 75-79. 